Pacific Journal of Mathematic 


\section{THE FLEXURE OF A NON-UNIFORM BEAM}

E. E. JONES

Summary. The flexure of a beam of non-uniform flexural rigidity and non-uniform loading is deduced by the use of the method of the Laplace transform, the results being in the form of a single equation involving integrals which are in a suitable form for evaluation, either numerically or otherwise. Two examples of practical importance are introduced to illustrate the method, and the results are also applied to determine the equation to the elastica of a beam supported by many rigid supports.

1. Introduction. The method of solution of linear differential equations by means of the Laplace transform was used by Jaegar [6] to deduce the deflection of a beam with concentrated loads along its length, the beam having uniform flexural rigidity and variable loading. These results were extended considerably by Thomson [10], who indicated that the Laplace transformation method led to the simplest approach to the beam problem. These results were obtained in the form of a single equation in terms of certain end conditions, and eliminated the necessity of determining the equations between points of discontinuity of load, and then connecting them at these points, [9], [1]. Thomson's results apply to problems concerning beams of uniform flexural rigidity, and in order to extend them to problems involving beams of varying and discontinuous cross-sectional inertia it was necessary to reduce these latter problems to the former by the introduction of an artificial modified loading of the beam, [4], [11]. This present paper indicates how the problem of the beam with non-uniform loading and flexural rigidity can be solved directly by the use of standard operational methods, an appeal being made only to well-known results in the calculus, [3, p. 257], [7, pp. 71, 82], [12].

It is assumed in this paper, that if $\mathscr{C} y(x)$ is the Laplace transform of $y(x)$, then

$$
\mathscr{L} y(x)=\int_{0}^{\infty} e^{-1 x} y(x) d x,
$$

and in conjunction with this the following theorem is also required:

$$
\mathscr{P} y_{1}(x) \mathscr{L} y_{2}(x)=\mathscr{L} \int_{0}^{x} y_{1}(u) y_{2}(x-u) d u
$$

Received March 26, 1954. 
if these integrals exist.

The results of the subsequent analysis can also be put into more convenient forms by the introduction of the unit step-function, defined by

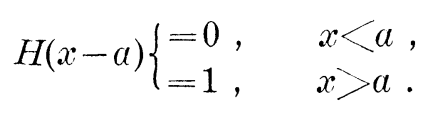

2. The beam under consideration is assumed to have $s$ sections, separated by the points $x_{n},(n=1,2, \cdots, s-1)$, the origin of coordinates being at one end of the beam, and the $x$-axis directed along the undistorted position of the beam. The $y$-axis is then taken in the direction vertically downwards, i.e. in the direction in which the gravitational forces act. The weight per unit length of the beam in the section $x_{n-1}<x<x_{n}$ is $w_{n}(x)$, and in order to simplify the notation, the flexural rigidity in this section is defined as $B_{n}^{-1}(x)$. The beam is subjected to $m$ concentrated loads $P_{n}$, acting at the points $X_{n},(n=1$, $2, \cdots, m)$.

In order to avoid assumptions regarding the distribution of the concentrated loads along an element of the beam at the positions where they act, it is more convenient to deduce an expression for the shear force acting on a right section of the beam in terms of the forces acting on the beam. If $z$ measures the bending moment at a point of the beam distant $x$ from the origin, then $-d z / d x$ measures the shear force at this point. Assuming that $z_{1}$ is the value of $d z / d x$ at the origin, then the shear force at a distance $x$ from this origin is given by the differential equation

$$
d z=z_{1}+\phi(x)
$$

where

$$
\phi(x)=\int_{0}^{x} w(u) d u+\sum_{X_{n}<x} P\left(X_{n}\right) .
$$

Here $\phi(x)$ is equal to an integral plus a step-function, and $P\left(X_{n}\right) \equiv P_{n}$. Any distributive loads can be included in $w$, which is a simply discontinuous function of $x$ of the form

$$
w(x)=\sum_{n=0}^{s-1}\left(w_{n+1}-w_{n}\right) H\left(x-x_{n}\right),
$$

where $w_{0}=0$.

Equation (2.1) can easily be deduced by resolving all the forces acting on the length of beam between the origin and the point distant $x$ 
from this origin normally to the beam in the direction of the $y$-axis. The Laplace transform of equation (2.1) is

$$
p \mathscr{C} z-z_{0}=z_{1} / p+\int_{0}^{\infty} \phi(x) e^{-p x} d x,
$$

it being sufficient to assume that $p>0$, since $\phi$ is bounded, and possesses a finite number of finite discontinuities in the range of integration. On rearranging equation (2.3),

$$
\mathscr{L} z=\frac{z_{0}}{p}+\frac{z_{1}}{p^{2}}+\frac{1}{p} \int_{0}^{\infty} \phi(x) e^{-p x} d x .
$$

The inverse of this equation is determined by using the convolution integral, giving

$$
z(x)=z_{0}+z_{1} x+\int_{0}^{x} \phi(u) d u .
$$

On integrating by parts, this leads to

$$
z=z_{0}+z_{1} x+[u \phi(u)]_{0}^{x}-\int_{0}^{x} u d \phi(u)=z_{0}+z_{1} x+\int_{0}^{x}(x-u) d \phi(u) .
$$

This equation expresses the bending moment $z$ at a point of the beam in terms of a Stieltjes integral, [13, chap I], and thus can be interpreted in a series form.

From equation (2.2), by substituting for $\phi(x)$ into the integral involved in equation (2.4),

$$
\int_{0}^{x}(x-u) d \phi(u)=\int_{0}^{x}(x-u) w(u) d u+\sum_{X_{n}<x}\left(x-X_{n}\right) P_{n},
$$

since contributions to the integral from the step-function only occur when $u$ passes through a point of discontinuity. Hence finally equation (2.4) takes the form

$$
z=z_{0}+z_{1} x+\int_{0}^{x}(x-u) w(u) d u+\sum_{n=1}^{m} P_{n}\left(x-X_{n}\right) H\left(x-X_{n}\right),
$$

where the last term in equation (2.5) has been modified by the use of the unit step-function.

The deflection $y$ at the point $x$ of the beam is given by the differential equation

$$
\frac{d^{2} y}{d x^{2}}=z(x) B(x)
$$

where 


$$
B(x)=\sum_{n=0}^{s-1}\left(B_{n+1}-B_{n}\right) H\left(x-x_{n}\right),
$$

with $B_{0}=0$. Here $B(x)$ is a simply discontinuous function of $x$, and $z(x)$ is defined by equation (2.6)

If $y_{0}=(y)_{x=0}$, and $y_{1}=(d y / d x)_{x=0}$, then by repeating the above process

$$
y=\frac{y_{0}}{p}+\frac{y_{1}}{p^{2}}+\frac{1}{p^{2}} Z^{2}(z B)
$$

whence

$$
y=y_{0}+y_{1} x+\int_{0}^{r}(x-u) z(u) B(u) d u,
$$

using again the property of the convolution integral.

By combining equations (2.6) and (2.7), the deflection of the beam can be written in the more convenient form

$$
\begin{aligned}
y=y_{0}+y_{1} x+\int_{0}^{x}(x-u)\left(z_{0}+z_{1} u\right) B d u & +\int_{0}^{x}(x-v) B d v \int_{0}^{v}(v-u) w d u \\
& +\sum_{n=1}^{m} P_{n} H\left(x-X_{n}\right) \int_{X_{n}}^{x}(x-u)\left(u-X_{n}\right) B d u .
\end{aligned}
$$

The integrals involved in this expression are all interpreted in the same manner, the range of integration is subdivided into intervals corresponding to the subdivisions of the functions $B$ and $w$, thus

$$
\int_{0}^{x}(x-u) B d u=\sum_{n=0}^{r-1} \int_{x_{n}}^{x_{n+1}}(x-u) B_{n+1} d u+\int_{x_{r}}^{x}(x-u) B_{r+1} d u
$$

when $x_{r}<x<x_{r+1},(0 \leq r \leq s-1)$. This integral may also be interpreted in the form

$$
\sum_{n=0}^{s-1} H\left(x-x_{n}\right) \int_{x_{n}}^{x}(x-u)\left(B_{n+1}-B_{n}\right) d u .
$$

Similar expressions occur for the remaining integrals although greater care must be taken over the subdivision of the last two integrals of equation (2.8).

It follows from equation (2.7) that

$$
\begin{aligned}
\frac{d y}{d x}= & y_{1}+\int_{0}^{x}\left(z_{\jmath}+z_{1} u\right) B d u+\int_{0}^{x} B d v \int_{0}^{n}(v-u) w d u \\
& +\sum_{n=1}^{m} P_{n} H\left(x-X_{n}\right) \int_{X_{n}}^{x}\left(u-X_{n}\right) B d u
\end{aligned}
$$


In any practical problem the values of the constants $y_{0}, y_{1}, z_{0}$, and $z_{1}$ can be deduced from the given end conditions, it being noticed that the equations apply along the whole length of the beam.

3. The first example illustrates the effect on the flexure of a beam of a variation in the flexural rigidity of the beam. The beam is assumed to have uniform loading $w$, and is freely supported at the same level at the ends $x=0, l$. The beam is subdivided and stepped in crosssection at the points $x_{n},(n=1,2, \cdots, 2 s)$, so that $x_{2 s+1}=l$, and these points are symmetrically placed with respect to the mid-point of the beam, such that

$$
\left.\begin{array}{l}
x_{2 s-n+1}+x_{n}=l \\
x_{2 s-n+1}-x_{n}=l_{n}
\end{array},\right\}(n=0,1, \cdots, s) .
$$

The flexural rigidity of the stepped beam is constant in each section, and is also symmetrically distributed, such that, in the usual notation, $B_{2 s-n+1}=B_{n+1},(n=0,1, \cdots, s)$.

The deflection of the beam at a point distant $x$ from one end, given by equation (2.8), is

$$
\begin{aligned}
y & =y_{1} x+z_{1} \sum_{n=0}^{2 s}\left(B_{n+1}-B_{n}\right) H\left(x-x_{n}\right) \int_{x_{n}}^{x} u(x-u) d u \\
& +\frac{w}{2} \sum_{n=0}^{2 s}\left(B_{n+1}-B_{n}\right) H\left(x-x_{n}\right) \int_{x_{n}}^{x} v^{2}(x-v) d v,
\end{aligned}
$$

since $y_{0}=z_{0}=0$ at $x=0$, where $y=d^{2} y / d x^{2}=0$. Also $y=d^{2} y / d x^{2}=0$ at $x=l$, hence from equation (2.6), $z_{1}=-w l / 2$, and from equation (3.2), after some reduction,

$$
y_{1}=\frac{w}{24 l} \sum_{n=0}^{2 s}\left(B_{n+1}-B_{n}\right)\left(l+3 x_{n}\right)\left(l-x_{n}\right)^{3} .
$$

The integrals of equation (3.2) are easily evaluated, and after substituting for $y_{1}$ and $z_{1}$, rearrangement leads to the final expression for the deflection

$$
\begin{aligned}
y= & \frac{1}{24} w x B_{1}\left(l^{3}+x^{3}-2 l x^{2}\right)+\frac{1}{48} w x \sum_{n=1}^{s}\left(B_{n+1}-B_{n}\right)\left(3 l^{2}-l_{n}^{2}\right) l_{n} \\
& -\frac{w}{384} \sum_{n=1}^{s} H\left(x-x_{n}\right)\left(B_{n+1}-B_{n}\right)\left(5 l^{2}+4 l x-4 x^{2}-2 l l_{n}+4 x l_{n}-3 l_{n}^{2}\right)\left(2 x-l+l_{n}\right)^{2} \\
+ & \frac{w}{384} \sum_{n=1}^{s} H\left(x-x_{2 s-n+1}\right)\left(B_{n+1}-B_{n}\right)\left(5 l^{2}+4 l x-4 x^{2}+2 l l_{n}-4 x l_{n}-3 l_{n}^{2}\right)\left(2 x-l-l_{n}\right)^{2} .
\end{aligned}
$$

When $x=l / 2$ this relation reduces to the result deduced by Hetényi, [5], using another method. 
4. The second example refers to a cantilever beam clamped horizontally at the end $x=0$, free at $x=l$, and loaded linearly according to the relation $w=m x$, where $m$ is a constant. The beam is subdivided and stepped in cross-section at $x_{n},(n=1,2, \cdots, s-1)$, in such a way that $B_{n}$ is constant in each section, but increases in magnitude as $n$ increases. A concentrated load acts at the mid-point $X$ of the end section $x_{s-1} \leq x \leq x_{s}$.

The equation governing the deflection of the beam reduces to

$$
\begin{aligned}
y & =\sum_{n=0}^{s-1} H\left(x-x_{n}\right)\left(B_{n+1}-B_{n}\right) \int_{x_{n}}^{x}(x-u)\left(z_{0}+z_{1} u\right) d u \\
& +m \sum_{n=0}^{s-1} H\left(x-x_{n}\right)\left(B_{n+1}-B_{n}\right) \int_{x_{n}}^{x}(x-v) d v \int_{0}^{v}(v-u) u d u \\
& +P H(x-X) \sum_{n=0}^{s-1}\left(B_{n+1}-B_{n}\right) \int_{X}^{x}(x-u)(u-X) d u,
\end{aligned}
$$

since $y_{0}=y_{1}=0$ at $x=0$, where $y=d y / d x=0$.

When $x=x_{s}=l$, then $z=d z / d x=0$, hence from equations (2.6) and (2.1),

$$
\begin{aligned}
& z_{1} l+z_{0}+P(l-X)+m l^{3} / 6=0, \\
& z_{1}+P+m l^{2} / 2=0 .
\end{aligned}
$$

Thus

$$
z_{0}=P X+m l^{3} / 3 \text {, and } z_{1}=-\left(P+m l^{2} / 2\right) \text {. }
$$

The deflection at any point $x$ of the beam then becomes

$$
\begin{aligned}
& y=\frac{1}{12} \sum_{n=0}^{s-1} H\left(x-x_{n}\right)\left(B_{n+1}-B_{n}\right)\left(x-x_{n}\right)^{2}\left\{2 P\left(3 X-x-2 x_{n}\right)+m l^{2}\left(2 l-x-2 x_{n}\right)\right\} \\
& +\frac{m}{120} \sum_{n=0}^{s-1} H\left(x-x_{n}\right)\left(B_{n+1}-B_{n}\right)\left(x^{5}-5 x x_{n}^{4}+4 x_{n}^{5}\right) \\
& \quad+\frac{P}{6} H(x-X) \sum_{n=0}^{s-1}\left(B_{n+1}-B_{n}\right)(x-X)^{3} .
\end{aligned}
$$

5. When a beam is constrained at various points along its length by means of rigid supports, the reactions at these points will occur in the equations for the flexture of the beam. It is thus necessary to eliminate, or at least to determine these reactions. A particular example will suffice to indicate the procedure. It is required to determine the form of the elastica of a beam of varying section clamped at each end, and supported at several points along its length, one of 
these supports being a distance $d$ out of alignment with the remainder.

There are $m$ supports, one at each of the points $X_{r},(r=1,2, \cdots$, $m)$, the beam being divided into $s$ sections at points $x_{r},(r=1,2, \cdots$, $s-1)$. The beam is clamped horizontally at $x=0$ and at $x=x_{s}=X_{s}$, and there $y=d y / d x=0$.

The following notation is introduced:

$$
\begin{array}{ll}
a_{r}=\int_{0}^{X_{r}}\left(X_{r}-u\right) B d u, & b_{r}=\int_{0}^{X_{r}}\left(X_{r}-u\right) u B d u, \\
c_{r}=\int_{0}^{X_{r}}\left(X_{r}-v\right) B d v \int_{0}^{v}(v-u) w d u, & d_{n r}=\int_{X_{n}}^{X_{r}}\left(X_{r}-u\right)\left(u-X_{n}\right) B d u,
\end{array}
$$

the integrals being interpreted as in $\S 2$.

If $P_{n},(n=1,2, \cdots, m)$, are the reactions at the supports, then from equations (2.8) and (2.9), at $x=0, y_{0}=y_{1}=0$, and at $x=x_{s}=X_{s}$, then

$$
\begin{aligned}
& z_{0} a_{s}+z_{1} b_{s}+c_{s}+\sum_{n=1}^{m} P_{n} d_{n s}=0, \\
& z_{0} a_{s}^{\prime}+z_{1} b_{s}^{\prime}+c_{s}^{\prime}+\sum_{n=1}^{m} P_{n} d_{n s}^{\prime}=0,
\end{aligned}
$$

where $a_{s}^{\prime}=\int_{0}^{X_{s}} B d u$, etc., i.e. the partial derivatives of the integrals with respect to $x$ at $x=X_{s}$.

Solving equation (5.1) for $z_{0}$ and $z_{1}$ we obtain

$$
z_{0}=f_{s}+\sum_{n=1}^{m} P_{n} F_{n s}, \quad z_{1}=g_{s}+\sum_{n=1}^{m} P_{n} G_{n s},
$$

where

$$
\begin{array}{rlrl}
f_{s} & =\left(c_{s} b_{s}^{\prime}-c_{s}^{\prime} b_{s}\right) /\left(a_{s}^{\prime} b_{s}-a_{s} b_{s}^{\prime}\right), & & g_{s}=\left(a_{s} c_{s}^{\prime}-a_{s}^{\prime} c_{s}\right) /\left(a_{s}^{\prime} b_{s}-a_{s} b_{s}^{\prime}\right), \\
F_{n s} & =\left(b_{s}^{\prime} d_{n s}-b_{s} d_{n s}^{\prime}\right) /\left(a_{s}^{\prime} b_{s}-a_{s} b_{s}^{\prime}\right), & G_{n s}=\left(a_{s} d_{n s}^{\prime}-a_{s}^{\prime} d_{n s}\right) /\left(a_{s}^{\prime} b_{s}-a_{s} b_{s}^{\prime}\right) .
\end{array}
$$

It is assumed that the supports are in line along $y=0$, with the exception of the support at the point $\left(x_{t}, d\right)$. If $\delta_{r t}=1$ when $r=t$, and is zero when $r \neq t$, then $y_{r}=d \delta_{r t}$, and from equation (2.8),

$$
-d \delta_{r t}-a_{r} f_{s}-b_{r} g_{s}-c_{r}=\sum_{n=1}^{m}\left\{a_{r} F_{n s}+b_{r} G_{n s}+d_{n r} H(n-r)\right\} P_{n} .
$$

This equation can be written in the matrix form

$$
p_{r n} P_{n}=q_{r}, \quad(r, n=1,2, \cdots, m),
$$

where 


$$
\begin{gathered}
p_{r n}=a_{r} F_{n s}+b_{r} G_{n s}+d_{n r} H(n-r), \\
q_{r}=-\left(d \delta_{r t}+a_{r} f_{s}+b_{r} g_{s}+c_{r}\right) .
\end{gathered}
$$

The matrix equation can be solved for $P_{n}$ by any of the standard methods [2, pp. 96-155], i.e. by an iterative process, or by forming a triangular matrix by premultiplying both sides of equation (5.2) by a suitable matrix and solving the resulting equations either directly or by considering the reciprocal matrix solution.

The elastica is determined by inserting the values of $P_{n}$ in equation (2.8), since $y_{0}=y_{1}=0$, and $z_{\text {, }}$ and $z_{1}$ are already known. The procedure is similar for other end conditions. When the reactions at the supports are known, it is also possible to determine the slope, the bending moment, and the shear stress at any point of the beam. All the integrals can be evaluated numerically, [8], or directly if the variation of $B$ and $w$ is in a simple form, and a tabular process can be readily set up.

\section{REFERENCES}

1. B. Eriksen, Beams of variable moment of inertia, Concr. Constr. Eng. 46, (1951), 177, 207.

2. R. A. Frazer, W. J. Duncan and A. R. Collar, Elementary matrices, 1st. edn. Cambridge Univ. Press, 1938.

3. M. F. Gardner and J. L. Barnes; Transients in linear systems, Vol. 1, 1st. edn., Wiley and Sons, 1942.

4. M. Hetényi, Deflection of beams of varying cross-section, J. Appl. Mech. 4, (1937), 49.

5. $\quad$ - Application of Maclaurin seres to the analysis of beams in bending, J. Frank. Inst. 254, (1952), 369.

6. J. C. Jaegar, The solution of one-dimensional boundary value problems by the Laplace transformation, Math. Gaz. 23, (1939), 62.

7. - An introduction to the Laplace transformation, 1st. edn., Methuen, 1949.

8. T. G. Morrison, Rapid computation of flexural constants, Proc. Amer. Soc. civ. Engrs. 79, (1953), Sep. No. 170.

9. N. O. Myklestad, A simple tabular method of calculating deflections and influence coefficients of beams, J. Aero. Sci. 13, (1946), 23.

10. W. H. Thomson, Deflection of beams by the operational method, J. Frank. Inst. 247, (1949), 557.

11. - Vibrations of slender bars with discontinuities in stiffness, J. Appl. Mech. 16, (1949), 203.

12. - Laplace transformation, 1st. edn., Prentice Hall, 1950.

13. D. V. Widder, The Laplace transform, 1st. edn., Princeton Univ. Press, 1946.

UNIVERSity OF NotTingham, ENGLAND. 


\section{PACIFIC JOURNAL OF MATHEMATICS}

\section{EDITORS}

\author{
H. L. Royden \\ Stanford University \\ Stanford, California \\ E. Hewite \\ University of Washington \\ Seattle 5 , Washington
}

\author{
R. P. Dilworth
}

California Institute of Technology Pasadena 4, California

\section{A. HorN*}

University of California

Los Angeles 24, California

\section{ASSOCIATE EDITORS}

\author{
H. BUSEMANN \\ HERBERT FEDERER \\ MARSHALL HALL
}

\author{
P. R. HALMOS \\ HEINZ HOPF \\ ALFRED HORN
}

\author{
R. D. JAMES \\ BORGE JESSEN \\ PAUL LÉVY
}

GEORGE PÓLYA

J. J. STOKER

KOSAKU YOSIDA

\section{SPONSORS}

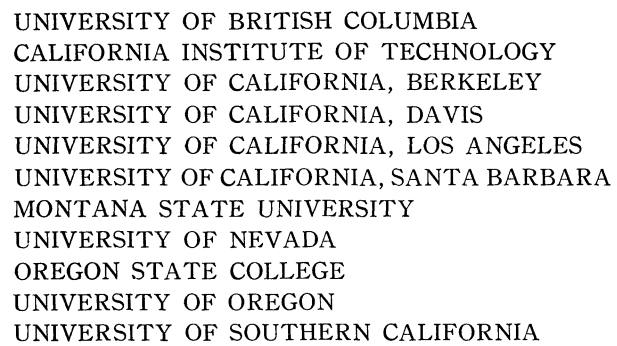

UNIVERSITY OF BRITISH COLUMBIA

CALIFORNIA INSTITUTE OF TECHNOLOGY

UNIVERSITY OF CALIFORNIA, BERKELEY

UNIVERSITY OF CALIFORNIA, DAVIS

UNIVERSITY OF CALIFORNIA, LOS ANGELES

UNIVERSITY OF CALIFORNIA, SANTA BARBARA

MONTANA STATE UNIVERSITY

UNIVERSITY OF NEVADA

OREGON STATE COLLEGE

UNIVERSITY OF OREGON

UNIVERSITY OF SOUTHERN CALIFORNIA

\author{
STANFORD RESEARCH INSTITUTE \\ STANFORD UNIVERSITY \\ UNIVERSITY OF UTAH \\ WASHINGTON STATE COLLEGE \\ UNIVERSITY OF WASHINGTON
}

AMERICAN MATHEMATICAL SOCIETY

HUGHES AIRCRAFT COMPANY SHELL DEVELOPMENT COMPANY

Mathematical papers intended for publication in the Pacific Journal of Mathematics should be typewritten (double spaced), and the author should keep a complete copy. Manuscripts may be sent to any of the editors. Manuscripts intended for the outgoing editors should be sent to their successors. All other communications to the editors should be addressed to the managing editor, Alfred Horn at the University of California Los Angeles 24, California.

50 reprints of each article are furnished free of charge; additional copies may be obtained at cost in multiples of 50 .

The Pacific Journal of Mathematics is published quarterly, in March, June, September, and December. The price per volume (4 numbers) is $\$ 12.00$; single issues, $\$ 3.50$; back numbers (Volumes $1,2,3)$ are available at $\$ 2.50$ per copy. Special price to individual faculty members of supporting institutions and to individual members of the American Mathematical Society: $\$ 4.00$ per volume; single issues, $\$ 1.25$.

Subscriptions, orders for back numbers, and changes of address should be sent to the publishers, University of California Press, Berkeley 4, California.

Printed at Kokusai Bunken Insatsusha (International Academic Printing Co., Ltd.) No. 10 1-chome Fujimi-cho, Chiyoda-ku, Tokyo, Japan.

* During the absence of E. G. Straus. 


\section{Pacific Journal of Mathematics}

\section{Vol. 5, No. $5 \quad$ BadMonth, 1955}

Henry A. Antosiewicz, A theorem on alternatives for pairs of matrice . . . . . 641

F. V. Atkinson, On second-order non-linear oscillation ............... 643

Frank Herbert Brownell, III, Fourier analysis and differentiation over real separable Hilbert spac .................................. 649

Richard Eliot Chamberlin, Remark on the averages of real function ...... 663

Philip J. Davis, On a problem in the theory of mechanical quadrature ... . . 669

Douglas Derry, On closed differentiable curves of order $n$ in $n$-spac ...... 675

Edwin E. Floyd, Boolean algebras with pathological order topologie ... . . 687

George E. Forsythe, Asymptotic lower bounds for the fundamental frequency of convex membrane ................................. 691

Israel Halperin, On the Darboux propert ................... 703

Theodore Edward Harris, On chains of infinite orde .............. 707

Peter K. Henrici, On certain series expansions involving Whittaker functions

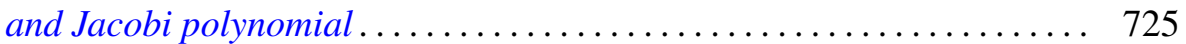

John G. Herriot, The solution of Cauchy's problem for a third-order linear hyperoblic differential equation by means of Riesz integral ......... 745

Jack Indritz, Applications of the Rayleigh Ritz method to variational



E. E. Jones, The flexure of a non-uniform bea ................. 799

Hukukane Nikaidô and Kazuo Isoda, Note on non-cooperative convex game.

Raymond Moos Redheffer and W. Wasow, On the convergence of asymptotic solutions of linear differential equation . . .

S. E. Warschawski, On a theorem of L. Lichtenstei ...........

Philip Wolfe, The strict determinateness of certain infinite game... 